Artículo de Investigación

Apuntes del CENES

ISSN 0120-3053

Volumen $34-\mathrm{N}^{\circ} .60$

julio - diciembre 2015

Págs. 215-246

\title{
Análisis de la dependencia fiscal de los municipios de sexta categoría del departamento de Boyacá, durante el periodo 1996-2012
}

Analysis of fiscal dependency of

municipalities of sixth category

in Boyacá, from 1996 to 2012

\author{
Análise da dependência fiscal dos \\ municípios de sexta categoria do Boyaca, \\ durante o período 1996-2012
}

Siervo Tulio Delgado Ruiz* Luis Enrique Acero Jiménez**

Fecha de recepción: 12 de marzo de 2015

Concepto de evaluación: 19 de mayo 2015

Fecha de aprobación: 25 de junio 2015

\footnotetext{
Economista. Magíster en Economía.Docente, Escuela de Economía, Universidad Pedagógica y Tecnológica de Colombia. Tunja, Boyacá - Colombia. Correo electrónico: siervo.delgado@uptc.edu.co

** Economista. Magíster en Economía. Analista de Estudios Económicos, Banco de la República, Agencia Tunja - Colombia. Correo electrónico: laceroji@banrep.gov.co
} 


\section{Resumen}

La Constitución de 1991 profundizó la descentralización fiscal al aumentar el volumen de transferencias del Gobierno central hacia el nivel territorial y redefinió las funciones de los distintos niveles de Gobierno, incrementando sus responsabilidades. La tributación que genera mayor recaudo está monopolizada por el Gobierno nacional, quedando pocas posibilidades de nuevos gravámenes a los gobiernos locales, los cuales se financian casi exclusivamente con transferencias, causándoles una alta dependencia financiera, en especial de aquellos cuya capacidad de generación de rentas propias es casi nula.

Palabras clave: dependencia fiscal, transferencias, esfuerzo fiscal, descentralización, autonomía municipal.

Clasificación JEL: H70, H72, H75, H76, H77

\section{Abstract}

The Constitution of 1991 has made fiscal decentralization deeper as it has augmented the number of transferences from the central government towards the territorial level of the State, apart from having redefined the functions of the different governmental levels and increased the responsibilities of the local governments. Revenues that generate the greater income are still monopolized by the central government, resulting in a diminished possibility for the local governments -who are financed almost solely by transferences from the central government- to impose new tax rates. This phenomenon causes the municipalities to be highly dependent from the central government, especially those who have a nearly inexistent capacity for generating their own revenues.

Keywords: fiscal dependency, transferences, fiscal effort, decentralization, municipal autonomy. 


\section{Resumo}

A Constituição de 1991 aprofundou a descentralização fiscal; para aumentar o volume de transferências do governo central para o nível regional e redefiniu os papéis dos diferentes níveis de governo, aumentando as suas responsabilidades. Tributação gera maior coleção é monopolizado pelo governo nacional, deixando pouca chance de novos impostos para os governos locais, que são financiadas quase exclusivamente através de transferências, provocando uma alta dependência financeira, especialmente aqueles cuja capacidade de gerar sua própria renda é quase nula. Portanto, é apropriado para analisar o nível de dependência dos municípios de sexta categoria de Boyacá e estabelecer causalidade que origina, com base em uma estimativa econométrica.

Palavras-chave: dependência fiscal, transferências, esforço fiscal, descentralização, autonomia municipal. 


\section{INTRODUCCIÓN}

El proceso de descentralización política, administrativayfiscal vivido enColombia desde finales de los años 80 , ha venido trasladando permanentemente a los entes territoriales las responsabilidades y competencias que estaban a cargo del Gobierno central, así como les ha dado participación en las principales rentas, especialmente aquellas provenientes de tributación al consumo, sin que estas últimas se compadezcan con el sinnúmero de compromisos que ahora deben asumir las administraciones locales. La adopción de este modelo desde los años 80 obedeció a «[...] una negociación con la clase política, que terminó en un reparto de recursos y competencias en el cual la nación cedió responsabilidades sobre todo en el gasto social, pero no cedió bases tributarias, de manera que el nivel nacional se comprometió a girar recursos mediante transferencias» (Giraldo, 2009, p. 144). En este contexto, se descentralizaron los gastos mientras el Gobierno central nacional se quedó con los ingresos, como forma de asegurar el cumplimiento de los compromisos financieros derivados de la deuda pública de orden nacional.

Este proceso ha estado marcado por varias reformas que, con el objetivo de asegurar el uso de los recursos en la financiación de servicios básicos como la salud y la educación, ha dado el carácter de destinación específica a estos recursos, lo que asegura su inversión pero a la vez genera una alta inflexibilidad en su destinación. Además, debido a que la tributación indirecta es la mayor generadora de recaudo, pero está monopolizada por el Gobierno nacional (IVA, sobretasa a los combustibles, 4x1000, etc.), son 
pocas las posibilidades de imposición de nuevos gravámenes que le quedan a los gobiernos locales, los cuales fijan su financiamiento casi exclusivamente en los dineros transferidos por el nivel central de Gobierno.

En este panorama se genera una alta dependenciafinanciera de los municipios, cuya capacidad de generación de rentas propias es casi nula, salvo los escasos recursos provenientes de los impuestos predial, sustentado sobre unos avalúos catastrales desactualizados, y de industria y comercio, aplicado a las pocas actividades comerciales y las casi inexistentes actividades industriales que se desarrollan en cada municipalidad.

Esta baja capacidad tributaria de los municipios para atender los compromisos de gasto lleva a que los gobiernos locales, gracias al modelo de liberalización financiera imperante, tengan que recurrir a un creciente endeudamiento, pignorando los escasos recursos propios que pueden generar, limitando así las posibilidades futuras de gasto social (Giraldo, 2009, p.146)

Esta restricción en la disponibilidad de recursos otorga un mínimo margen de maniobra a los gobiernos locales, cuya gestión se limita al uso de los recursos transferidos en las destinaciones asignadas legalmente.

Por lo anterior, resulta oportuno hacer un estudio sobre el nivel de dependencia de los municipios de Boyacá, cuya mayoría se clasifica en sexta categoría, de acuerdo con los parámetros establecidos por la Ley 617 de 2000, y establecer la posible relación de causalidad que origina tal dependencia. En ese sentido, el presente artículo aborda esta circunstancia al analizar la dependencia fiscal de los municipios de sexta categoría del departamento de Boyacá, con el fin de establecer sus determinantes, durante el periodo 1996-2012.

Inicialmente se presenta una revisión teórico-conceptual del actual enfoque de política fiscal y finanzas públicas aplicado en Colombia, seguida de una corta descripción de los antecedentes de la descentralización en el país. A continuación se muestran los resultados de un ejercicio de estimación econométrica para determinar la relación de causalidad de la dependencia fiscal de los municipios objeto de estudio, utilizando la metodología de datos de panel, y se finaliza con las conclusiones del estudio.

\section{ESTADO Y RACIONALIDAD ECO- NÓMICA}

En primera instancia es importante comprender lo que implica el proceso de descentralización, que si bien es cierto promueve la participación en la toma de decisiones a nivel local, también lo es que trae grandes implicaciones, especialmente en lo que respecta a las limitaciones de los gobiernos territoriales para obtener los recursos necesarios para 
financiar sus responsabilidades de gasto. Además, la descentralización no es un proceso aislado sino que forma parte de un modelo económico que viene siendo aplicado en América Latina, del cual Colombia no es la excepción, y que abarca varios campos dentro de la actividad económica.

Es por ello que la estructura de las finanzas públicas en Colombia, hoy en día, obedece a la aplicación de los programas de ajuste y reformas estructurales implementadas desde los años ochenta por el FMI, el BM y el BID, bajo las premisas de la primacía del mercado y el desmonte del intervencionismo estatal. Ello conduce al logro del tan anhelado equilibrio fiscal, que se alcanza gracias al incremento de impuestos, y los precios de los bienes públicos (tarifas), acompañados del recorte en el gasto gubernamental (Giraldo, 2009).

Tales programas surgen como respuesta a las políticas implementadas desde los años cincuenta, que fueron ineficientes y generadoras de renta en beneficio de determinados sectores, derivados de la aplicación del modelo se sustitución de importaciones, situación que derivó en la crisis económica en los ochenta, reflejada en la crisis de la deuda.

En este punto de la historia el modelo intervencionista llegó a un punto de quiebre, se hizo insostenible fiscalmente e ineficiente en el cumplimiento de sus funciones, por lo que las ideas de Keynes dejaron de ser funcionales al nuevo contexto de la economía mundial y ello justificó un nuevo cambio de paradigma (Giraldo, 2009). Al respecto, autores como James Buchanan (1993), afirmaron que las ideas keynesianas sobre la inestabilidad intrínseca de la economía habían propiciado, por un lado, el activismo y manejo discrecional de la política fiscal y, por otro, el abandono de la creencia sobre la necesidad de mantener en equilibrio el presupuesto y lograr la reducción de la deuda.

En este sentido, las reformas introducidas tienen dos dimensiones: Una orientada a disminuir la intervención del Estado para dejar un mayor juego al mercado, y cuando esta intervención sea indispensable, debe realizarse con los criterios e instrumentos más cercanos a los del mercado y, la otra, que apunta a que las reformas del Estado se complementan con reformas en los mercados, disminuyendo las distorsiones derivadas del control e injerencia estatal, logrando la llamada «(...) flexibilización, que se expresa en el mercado de bienes con la apertura comercial, en el de capitales con la desregulación financiera, y en el laboral con la flexibilización de la relación salarial.» (Giraldo, 2009, p. 27)

Desde esta perspectiva, no existe ninguna incompatibilidad entre el manejo adecuado por parte del Estado de las fallas del mercado y la función de preservar la competencia. «Prácticamente cualquier función del Estado es compatible con la competencia o con condiciones análogas 
a la competencia. [...] Lo que hay es Estado y sector privado con competencia o sin ella» (Wiesner, 1997, p. 12).

De acuerdo con ello, Wiesner (1997), desde la visión neoinstitucionalista, plantea que el Estado se concibe como el resultado de un «contrato» entre la sociedad civil, constituida por agentes económicos y agentes políticos, y el sector público, quien deberá cumplir funciones de «árbitro neutral» en los procesos de producción, distribución y consumo de la riqueza, el ingreso y las oportunidades. Así las cosas, en dicho contrato la sociedad civil actual como «el principal» que encarga al «agente», o sea al Estado, la labor de asegurar el funcionamiento y cumplimiento de un conjunto de reglas.

En esta perspectiva, las finanzas públicas constituyen una redistribución de la asignación que el mercado hace de los recursos de una sociedad, pero como esa redistribución se considera una distorsión para la economía, el accionar del Estado debe regirse por principios de eficiencia y objetividad (propios del mercado) para hacer esa asignación de recursos.

La aplicación del enfoque neoclásico supone una reorientación de las políticas públicas, en el sentido de lograr ciertos objetivos como «(...) la disciplina fiscal y financiera, focalización del gasto y orientación de subsidios a la demanda, fijación de impuestos neutrales, privatización y descentralización fiscal (Giraldo, 2009, p. 35).» Frente a este último criterio, se entiende la descentralización desde la óptica del mercado «(...) en la medida en que se concibe como un mecanismo para introducir competencia de mercado entre las regiones y localidades, $\mathrm{y}$ permitir una relación más cercana entre la institución que presta el servicio y el usuario» (Giraldo, 2009, p. 36).

En Colombia, esta visión del Estado neoclásico fue adaptada por los economistas adeptos a la llamada escuela neoinstitucionalista, los cuales estuvieron detrás de la reforma estructural implementada en el Estado, a nivel nacional y territorial, introducida en la Constitución de 1991. Según Wiesner (1997, p. 18), uno de los principales exponentes de este grupo, «[...] hay mucho en común entre la Escuela Neoinstitucional y la Escuela de Chicago. Este parentesco conceptual y operacional debe ser tenido en cuenta para que no se identifique a la Escuela Neoinstitucional como la antítesis del modelo Clásico o Neoclásico ni como la negación de los postulados de la llamada Escuela de Chicago».

En ese sentido, el principio de la eficiencia, como orientador del actuar de todo agente económico, incluido el Estado, se manifiesta en el uso de un recurso para financiar un determinado gasto, siendo eficiente no solo por su destinación sino por el origen y naturaleza del mismo. De ahí que, cuando un recurso proviene de los mercados, o 
de condiciones similares a este, «[...] se puede anticipar que habrá mayor eficiencia que cuando el financiamiento proviene de, por ejemplo, impuestos, rentas de destinación específica o transferencias automáticas y sin mayor condicionalidad» (Wiesner, 1997, p. 14).

Con base en este criterio, Wiesner (1997, p. 14) considera que en Colombia, durante los últimos años, la proporción del gasto público financiado con ingresos tributarios ha venido cayendo, en términos relativos, en todos los niveles del sector público, pero con una mayor intensidad en el nivel territorial, pues allí las transferencias están financiando una proporción creciente del gasto local.

Ante este panorama, el modelo teórico propuesto para Colombia, sustentado en el proceso descentralizador, contempla que las acciones de gasto público estén enmarcadas dentro de procesos de «escogimiento público» pero aplicados al ámbito territorial.

En materia de escogimientos públicos, como elección racional para resolver fallos de mercado, existen las llamados «escogimientos públicos locales» en contraste con los nacionales. Para Wiesner (1997), los últimos hacen referencia a la asignación de los recursos públicos para generar bienes públicos nacionales, en tanto que los primeros hacen referencia a bienes públicos locales y a políticas territoriales $\mathrm{o}$ municipales. En este último caso, dada la cercanía entre el consumidor local y el proveedor público local (Gobierno municipal), se argumenta que habrá mayor eficiencia económica y mayor transparencia política (p. 92).

Se supone que la revelación de preferencias por los bienes públicos y las políticas locales, por ser más directas, va a ser menos imprecisa que a nivel nacional. Por su parte, la respuesta desde el lado de la oferta pública debería estar no muy lejos de ser eficiente. El escogimiento público local está más expuesto a la competencia que el escogimiento público nacional, debido, en particular, a que los consumidores pueden «votar con los pies» y obligar a la oferta a competir con eficiencia y equidad para no perder ciudadanos o consumidores. (Tiebout, 1956, p. 24)

Este argumento sirve de justificación para el proceso de descentralización de los ingresos y gastos públicos y de las decisiones relacionadas con ese gasto y la gestión pública local, pilares de la relación entre los distintos niveles de gobierno y entre los agentes económicos en el ente territorial.

Para asegurar la ventaja potencial de la decisión local frente a la nacional es necesaria la existencia de una condición de carácter institucional y fiscal, la cual consiste en que «(...) gran parte del financiamiento del gasto público local provenga de ciudadanos locales» (Wiesner, 1997, p. 92), pues si el financiamiento se sustenta en 
transferencias, con pocas restricciones de uso, no será razonable suponer que los contribuyentes locales se interesen por vigilar la calidad del gasto que se financia con tributos pagados por otros. Por tanto, una de las principales exigencias del modelo de escogimiento público local está en asegurar que una buena parte del financiamiento del presupuesto local se origine en ingresos tributarios propios.

La importancia del financiamiento propio difícilmente puede ser exagerada. Su significado radica no solo en proveer recursos adicionales sino en suministrar las externalidades que hacen posible satisfacer las otras condiciones básicas. Estas son: el fortalecimiento institucional, la mejoría de la información, la transparencia en los procesos políticos y fiscales, y la capacidad de hacer evaluaciones reales a la gestión pública (Wiesner, p. 93).

Se sigue así el principio de la subsidiariedad, que significa que el servicio sea suministrado por el nivel inferior de Gobierno que pueda proveerlo y financiarlo, de manera que los bienes y servicios provistos por el nivel nacional pasan al nivel intermedio (departamentos o provincias) y de ahí al nivel municipal y del nivel municipal a las instituciones (colegios, hospitales, empresas de servicios públicos, etc.). Y si las instituciones se financian en el mercado, por medio de la venta de bienes y servicios, la intervención estatal sobra, siendo preferible que tales actividades queden por completo por cuenta del sector privado.

De los principios anteriores puede deducirse que focalización, subsidios a la demanda y descentralización, son políticas que, la mayoría de las veces, están estrechamente vinculadas. Subsidiar la demanda implica orientar los recursos directamente a los pobres, incluso a los más pobres de ellos mediante los sistemas de focalización, dirigiendo las ayudas económicas a estas personas sin pasar por las administraciones territoriales, que proveen bienes y servicios sociales, pero que para ello deben autofinanciarse.

Ahora bien, desde la teoría neoclásica se distinguen tres tipos de descentralización: ${ }^{1}$

La descentralización administrativa, que surge cuando se trasladan funciones y puede darse en dos casos: cuando pasan del nivel central nacional al descentralizado (establecimientos públicos, por ej.), o cuando se trasladan del nivel nacional al territorial. Sin embargo, tal traspaso de funciones (gasto) debe tener implicaciones fiscales (ingresos).

La descentralización política, que tiene un carácter vertical al trasladar ciertas

Esta clasificación se hace con base en los planteamientos de César Giraldo (2009), la cual corresponde al análisis de la descentralización a la luz del modelo neoclásico actual. 
responsabilidades políticas a los entes territoriales, responsabilidades que también implican recursos hacia los niveles subnacionales, alcanzando su máximo avance con la elección popular y directa de los gobernantes locales.

Y la descentralización fiscal, que indica la transferencia de un porcentaje de los recursos que recauda el Gobierno nacional a los entes territoriales para poder financiar las funciones que se trasladan por la descentralización política y administrativa.

La descentralización también se manifiesta mediante el fomento de la participación ciudadana, empoderando a las comunidades para que se vinculen a la determinación de algunas políticas a nivel territorial, así como para exigir a sus gobernantes la rendición de cuentas sobre su gestión. Con esto, a juicio del Banco Mundial, se rompen las trabas al ascenso social y a la actividad económica que impone el Estado y las instituciones sociales (Giraldo, 2009, p. 37), buscando así la igualdad ante la ley y la participación generalizada de los individuos, en un aparente tratamiento equitativo por parte del Estado.

Otro elemento que trae consigo el modelo es la búsqueda del equilibrio fiscal, gracias a la reducción de obligaciones de gasto, acompañada de una tributación eficiente, a lo que se agrega la eliminación de los monopolios estatales (otra distorsión), generando un entorno favorable, tanto en lo macro como en lo micro, para la actividad económica «eficiente», en el mejor sentido neoclásico del término.

Con la Constitución de 1991, Colombia introdujo varias reformas fiscales dirigidas a desconcentrarelgastonacional y mejorar la cobertura y eficiencia de la provisión de bienes públicos, redefiniendo las responsabilidades de gasto de todos los niveles de Gobierno y modificando el sistema de transferencias del nivel central al territorial, pese a que este nuevo sistema, al elevar los niveles de gasto, incrementó también los desequilibrios fiscales en ambos niveles

Como semencionóalinicio del artículo, el modelo descentralizador fue introducido en Colombia a mediados de los años 80 y fue profundizado con la Constitución de 1991, donde se desarrolla a fondo con el fin de introducir criterios de mercado a la provisión de bienes públicos. Así, los agentes cuando eligen donde ubicarse expresan sus preferencias al comparar lo que les brinda la localidad frente al precio en impuestos de tales beneficios, tal y como lo hacen en el mercado de bienes privados (Wiesner, 1992, p. 52), de manera que «(...) las ciudades menos competitivas expulsarán recursos productivos y las competitivas los atraerán» (Giraldo, 2009, p. 139).

Por esta razón, como se anotó atrás, un criterio que justifica la descentralización es la subsidiariedad, de manera que la mayor cercanía ente la oferta y la demanda de bienes públicos, más la 
movilidad de los factores de producción, lleva a una asignación óptima de los recursos, a la vez que genera una competencia entre los territorios por ofrecer mejores condiciones a los agentes privados, quienes querrán mayores niveles de gasto público a menores precios en impuestos. En consecuencia, los municipios prefieren las reducciones o exenciones tributarias a la actividad económica, para no ahuyentar la inversión privada, pues como lo indica el FMI (2001, p. 96) «[...] algunos sistemas tributarios son tan complicados e ineficientes que no permiten obtener un ingreso fiscal suficiente, y además distorsionan los incentivos para trabajar y ahorrar, con consecuencias deletéreas para el crecimiento económico».

Esta lógica indica que «(...) la descentralización de los ingresos supone dos tipos de reformas, una autonomía territorial para la creación de impuestos locales y una mayor distribución del conjunto de impuestos existentes entre las entidades territoriales y el nivel central.» (Restrepo, 2004, p. 88). Sin embargo, en Colombia el énfasis en la búsqueda del desarrollo económico y social ha recaído más «(...) en la cantidad de los recursos y su distribución o reparto que en la calidad de las políticas globales, y mucho menos en el papel de las instituciones y en la capacidad de las restricciones de economía política para distorsionar el proceso de creación de riqueza y de distribución de oportunidades» (Wiesner, 1997, p. 18).
Al revisar históricamente la descentralización en Colombia, según Giraldo (2009, p. 144), se identifican dos fases: la de los años ochenta, cuando se inicia su aplicación, durante la cual se cedieron responsabilidades, competencias y recursos a los gobiernos locales, sobre todo en áreas sociales, manteniendo el recaudo el nivel central y transfiriendo a las regiones parte del mismo. La otra fase, es la actual, y constituye una recentralización, ya que «(...) de una parte se recentralizan los instrumentos financieros mediante controles al endeudamiento territorial y la destinación de las transferencias a los gobiernos subnacionales $y$, de otra parte, se recentraliza el gasto social a través de programas administrados por el ejecutivo nacional».

De acuerdo con esta lógica, es el municipio la expresión del Estado más cercana al territorio y tiene, por Constitución y mandatos legales, grandes responsabilidades en educación, salud y agua potable, entre otros, comenzando en Colombia desde 1986 un discurso y una legislación en pro de la descentralización, y ella se ha constituido en elemento central de la apuesta democratizadora de la sociedad colombiana. Sin embargo, dado que del total de municipios del país, 995 están clasificados en sexta categoría (de acuerdo con la Ley 617 de 2000), lo que implica serias restricciones presupuestales, «(...) hoy es claro que no todos los municipios han estado en condiciones de cumplir sus funciones y 
coadyuvar a concretar el Estado social de derecho» (Caballero, Galvis \& García, 2012, p. 3).

De tal manera que los gobiernos locales, ante responsabilidades de gasto cada vez más elevadas y un recaudo tributario casi inflexible, pues los impuestos de mayor eficiencia desde el recaudo son de orden nacional (renta, IVA, transacciones financieras, patrimonio), quedan con una baja capacidad de generar recursos propios, ante lo cual surge el endeudamiento como la fuente más conveniente para obtención de recursos, erigiéndose el sector financiero como el nuevo financiador de las gestión pública local, con las implicaciones que ello trae para la autonomía territorial. En esa lógica, el Ministerio de Hacienda no gira los recursos que requieren los entes territoriales, pero sí les da el aval para que puedan acudir a las entidades financieras, generalmente privadas, en busca de recursos de crédito.

\section{CATEGORIZACIÓN TERRITORIAL}

Fue el mismo Estado, a través del Legislativo, el que estableció la categorización de los entes territoriales, con base en dos criterios: población e ingresos corrientes de libre destinación. Así, la Ley 617 de 2000, en su artículo 2 (el cual modificó el art. 6 de la Ley 136 de 1994) fijó las seis categorías para clasificar los distritos y municipios, correspondiendo la sexta categoría a «Todos aquellos distritos o municipios con población igual o inferior a diez mil (10.000) habitantes y con ingresos corrientes de libre destinación anuales no superiores a quince mil (15.000) salarios mínimos legales mensuales.» Sin embargo, en el parágrafo 1 del mencionado artículo se determinó que «Los distritos o municipios que de acuerdo con su población deban clasificarse en una categoría, pero cuyos ingresos corrientes de libre destinación anuales difieran de los señalados en el presente Artículo para la misma, se clasificarán en la categoría correspondiente a los ingresos corrientes de libre destinación anuales».

Se entienden como ingresos corrientes de libre destinación, los ingresos corrientes excluidos de rentas de destinación específica (Herrera, 2003), y la Ley 617 de 2000 busca que sean fundamentalmente los financiadores de los gastos de funcionamiento de las entidades territoriales. Y la fuente principal de recaudo de dichos ingresos corrientes son los ingresos tributarios, correspondientes a los impuestos de carácter municipal, es decir, «obligaciones pecuniarias que el Estado impone a los asociados y cede a los municipios, sin contraprestación directa ni personal, que pueden ser directos, cuando gravan la renta o el patrimonio, $\mathrm{o}$ indirectos, cuando gravan el gasto o el consumo» (Herrera, 2003, p. 9).

La restricción de los entes territoriales más pequeños, presupuestalmente hablando (entiéndase los de sexta categoría), para generar recursos propios 
aumenta el grado de dependencia de los mismos frente a los giros del Gobierno central, a la par que reduce su margen de maniobra frente al uso de los mismos. Así lo confirma el DNP al hacer el informe sobre el desempeño fiscal de los departamentos y municipios (DNP, 2011, p. 24):

Se puede corroborar que los ingresos propios (tributarios y no tributarios) pesan poco en los municipios y departamentos de categorías de menor tamaño poblacional y menores ingresos, mientras que son más importantes en los de categoría especial, primera y segunda, en contraste, la financiación del gasto en estas categorías de entidades está determinada por las fuentes exógenas como lo son las transferencias (inversión y funcionamiento) y las regalías.

Este esquema obedece a que el gobierno central debe concentrar las finanzas nacionales en un gasto que considera inflexible, priorizando el pago de la deuda, interna y externa, por lo cual debe descentralizar los gastos más no los ingresos, pues éstos deben quedar en el nivel central para dar cumplimiento a los compromisos financieros. En consecuencia, los requerimientos de las comunidades locales no logran ser cubiertas por las transferencias que gira la nación y «(...) se presenta un divorcio entre las necesidades locales y los recursos locales, de manera que no se hace transparente el proceso de elección pública en cuanto a que las decisiones locales no reflejan el costo de adoptarlas.» (DNP, 2011, p.145).
Por esto, autores como Wiesner (2006) y Clavijo, Vera y Vera (2013), plantean que Colombia tiene una alta inflexibilidad en el gasto, generada por los compromisos asumidos tanto constitucional como legalmente, especialmente por los compromisos fijados al Gobierno nacional en la Constitución de 1991 y la interpretación activista que han dado en sus sentencias las Cortes, en particular la Constitucional, a las responsabilidades que debe asumir el Estado.

La teoría tradicional sostiene que los bienes públicos que benefician a ciertos grupos de la población deben ser provistos por los gobiernos locales. De esta manera se garantiza una relación directa entre los costos y los beneficios asociados a dichos bienes. En contraste, los bienes públicos de cobertura nacional, como la justicia y la defensa nacional, al igual que las políticas de estabilización económica y de redistribución del ingreso corresponden a la lista de funciones del gobierno central. Además, se sugiere que $«(\ldots)$ cuando la base tributaria responde al diferencial de tarifas, los gobiernos locales deben imponer impuestos que reflejen el costo del bien público» (Iregui, Ramos \& Saavedra, 2001, p. 5). Así las cosas, si se tiene en cuenta lo expuesto por Rincón, Ramos y Lozano (2004), en cualquier nivel del Estado (nacional o territorial), dentro de los ingresos totales, los tributarios son los que permiten determinar la capacidad intertemporal del Gobierno para financiar el gasto y que en últimas, para mantener o aumentar dicho gasto se 
debe generar, prioritariamente, ingresos tributarios permanentes.

En este contexto, el neoclasisismo, inspirado en la racionalidad, concibe la descentralización como parte del proceso de globalización, con el fin de favorecer la libre movilidad del capital internacional e incentivar las demandas sociales, en especial las dirigidas a los gobiernos locales, los cuales, al no disponer de los recursos propios suficientes, deben acudir a un mercado financiero ávido de colocar recursos a tasas de interés elevadas, que son respaldados por ingresos tributarios territoriales, que al ser pignorados limitan la actuación pública en vigencias futuras. Al desaparecer la regulación y existir absoluta libertad en los mercados financieros, el endeudamiento permite la renta especulativa a partir de la captura de los ingresos públicos.

Dentro de este marco, la descentralización está constreñida por las políticas contraccionistas del Banco de la República, con miras a controlar la inflación y el compromiso del Gobierno por reducir el déficit fiscal (regla fiscal), dificultando el aumento en los giros de transferencias. Con esa finalidad tuvo acogida la argumentación del institucionalismo que logró que se adoptara constitucionalmente el principio de presupuestos equilibrados y se expidiera una norma de ajuste (Ley 1473 de 2011) que permitiera mantener el equilibrio presupuestario dentro del año fiscal, así como establecer las acciones por tomar en caso de que el objetivo se incumpliera (Buchanan, 1993). El propósito era eliminar la capacidad que tenían los políticos de manipular el sistema fiscal y económico para su beneficio, restableciendo los limites dentro de los cuales debían actuar los legisladores, basados en criterios de «racionalidad».

Es así como los escogimientos públicos reflejan más los intereses «racionales» de quienes toman las decisiones públicas que de los de aquellos a quienes se supone que benefician esas decisiones. Por esto es que «(...) la teoría del «public choice» puede ser definida como la aplicación del modelo de la «rational choice» a la ciencia política y a los procesos políticos. Es la aplicación del modelo neoclásico de teoría económica a la política» (Wiesner, 1997, p. 19).

No obstante, en Colombia, la estructura de la organización social, económica y política ha sido construida más sobre la base de una normatividad abstracta que sobre la base de una realidad empírica, sobre la conducta real de los agentes económicos y políticos. Aquí el «rational choice» no es el principal determinante de la conducta humana (Wiesner, p. 17).

De manera paradójica, la adopción del proceso de descentralización desde la década del ochenta sepultó las políticas de desarrollo regional, a cambio del interés por la programación territorial del gasto público social (Restrepo, 2004, p. 88). En este esquema es 
primordial el papel que han cumplido las transferencias.

\section{ANTECEDENTES DE LA DESCEN- TRALIZACIÓN EN COLOMBIA}

Durante casi todo el siglo XX Colombia se caracterizó por tener un sistema fiscal centralizado, en el cual el Gobierno nacional era el principal recaudador de impuestos y proveedor de bienes y servicios públicos. Si bien este proceso se inició con la consolidación del Estadonación, consagrado en la Constitución de 1886, su fortalecimiento ocurrió solo hasta después de la Segunda Guerra Mundial, tiempo en el cual el Gobierno central canalizó a su favor los ingresos fiscales más importantes y asumió la mayoría de los gastos (Iregui, Ramos \& Saavedra, 2001, p. 4).

El primer intento de reasignación de funciones entre los diferentes niveles de gobierno fue el proyecto de acto legislativo presentado por la administración López en 1976, con el cual se pretendían estabilizar las finanzas regionales mediante el fortalecimiento de las rentas propias y la redefinición de competencias de los departamentos y municipios. Aunque dicho proyecto no prosperó, allí se dejaron las bases para reformas posteriores como la Ley 14 de 1983 y la Ley 12 de 1986 (Iregui, Ramos \& Saavedra, 2001, p. 4).

El Gobierno Turbay reconoció de nuevo el problema del excesivo centralismo y de la falta de autonomía regional, por lo que en su plan de desarrollo señaló la descentralización como uno de los objetivos de política económica y como un instrumento para favorecer la autonomía de los entes territoriales, por lo que

buscaba reasignar recursos y redefinir competencias entre el nivel central y las regiones, evitando que el financiamiento de los departamentos y de los municipios dependiera exclusivamente de las transferencias nacionales. En ese sentido, se aspiraba a que las regiones aprovecharan en mayor medida su potencial tributario, mediante un mayor esfuerzo fiscal, lo cual redundaría en una menor dependencia de los aportes nacionales. (Iregui, Ramos \& Saavedra, 2001, p. 8).

Fue la administración Betancur la que realmente impulsó las primeras reformas importantes en materia de descentralización, mediante la Ley 14 de 1983, la cual tenía como objeto elevar el nivel de recaudos territoriales mediante la simplificación y racionalización del sistema impositivo de los departamentos y municipios. Esta reforma se adoptó justamente en un momento en el que se evidenciaba un grave deterioro en las finanzas del Gobierno nacional central a consecuencia de la significativa expansión del gasto corriente, mientas en el entorno latinoamericano estallaba la crisis de la deuda externa.

La Ley 12 de 1986, también expedida durante este mismo Gobierno, 
estableció el aumento progresivo en la participación municipal sobre el recaudo del impuesto al valor agregado (IVA). Si bien esta ley aumentó el volumen de recursos transferidos a los municipios, la autonomía local sobre su manejo era cuestionable (Iregui, Ramos \& Saavedra, 2001, p. 9). La ley definió explícitamente las actividades a las cuales deberían destinarse los recursos cedidos por la nación y en gran medida condicionó las transferencias al esfuerzo fiscal observado en el recaudo del impuesto predial.

En suma, las reformas fiscales de los ochenta tuvieron dos objetivos fundamentales: uno, el interés del Gobierno por descongestionar su presupuesto de algunas de las responsabilidades de gasto territorial en un momento de crisis y deterioro de las finanzas nacionales; y el otro, el deseo del Gobierno nacional de ampliar la cobertura y de mejorar la calidad y la eficiencia del gasto público (Iregui, Ramos \& Saavedra, 2001, p. 9).

Si bien durante la década del ochenta no hubo cambios significativos en materia de descentralización fiscal, en el terreno político se dieron avances importantes que condujeron a la elección popular de alcaldes en 1986. Esta reforma le dio más elementos a la ciudadanía para participar en la toma de decisiones de interés municipal. En teoría, se buscaba «(...) reducir la distancia entre el ciudadano y su gobernante con el fin de fortalecer el vínculo de responsabilidad política local e inducir el uso eficiente de los recursos» (Wiesner, 1997, p.103).

Los países pueden adoptar dos modelos fiscales: un sistema fiscal en el cual los gobiernos territoriales tienen plena autonomía en el gasto y en el ingreso, donde los impuestos locales financian los bienes públicos locales y el Gobierno central se encarga de la defensa nacional y la redistribución del ingreso. En el otro modelo, se concibe un sistema fiscal centralizado en el cual el Gobierno nacional es el principal recaudador de impuestos y el proveedor de los bienes y servicios públicos locales y nacionales. Frente a ellos, a pesar del proceso descentralizador implementado, el sistema fiscal colombiano se encuentra más cerca del modelo centralizado, ya que los gobiernos departamentales y municipales no tienen autonomía para establecer impuestos, pues si bien es cierto que el Congreso ha cedido algunos de los impuestos nacionales a los gobiernos territoriales, el establecimiento de bases gravables y rangos de tarifas ha correspondido exclusivamente al Legislativo. (Iregui, Ramos \& Saavedra, 2001, p. 9).

Adicionalmente, «(...) la cesión de impuestos ha estado sujeta a que los recursos deben destinarse a rubros de gasto determinados por Ley. Un gran porcentaje del gasto local no resulta de decisiones autónomas, porque buena parte de este se financia con recursos provenientes de transferencias con destinación específica del gobierno 
nacional central.» (Iregui, Ramos \& Saavedra, 2001, p. 10).

En cuanto a descentralización fiscal se refiere, la Constitución de 1991 y sus normas reglamentarias, aumentaron el volumen de transferencias del Gobierno central hacia el nivel territorial y redefinieron las funciones de los distintos niveles de Gobierno, aumentando las responsabilidades de los gobiernos locales. Así, el artículo 356 definió el destino de los recursos del situado fiscal y fijó las pautas para la distribución de estos recursos entre los gobiernos departamentales y los distritos especiales. Así mismo, este artículo estableció que no se «(...) podrán descentralizar responsabilidades sin la previa asignación de los recursos fiscales suficientes para atenderlas.» Si bien el artículo señala que las «participaciones» municipales se destinan a la inversión social, no definió los programas específicos que se financian con estos recursos (Iregui, Ramos \& Saavedra, 2001, p. 11). La Ley 60 de 1993 definió concretamente las funciones de los departamentos y municipios, la distribución territorial del situado fiscal y de las participaciones y los criterios que deben seguir las entidades territoriales para la asignación de los recursos transferidos por la nación, estructura de distribución que fue modificada luego por la Ley 715 de 2001, previa reforma constitucional que lo posibilitó, y regenta hoy día el llamado sistema general de participaciones (SGP).
En el caso del situado fiscal, la Ley 60 de 1993 señaló de nuevo que el 15 $\%$ de la transferencia se distribuye en partes iguales entre los departamentos y los distritos especiales, y el $85 \%$ restante se asigna de acuerdo con una fórmula que tiene en cuenta criterios de «(...) eficiencia fiscal y administrativa y la demanda actual y potencial de los servicios de salud y educación por parte de la población».

Para el caso de las transferencias a los municipios, la Ley 60 de 1993 estableció que su asignación se haría con base en el número de habitantes con necesidades básicas insatisfechas, el grado de pobreza relativa de las municipalidades e indicadores de eficiencia fiscal y administrativa. Sin embargo, debido a los manejos poco claros que se habían dado antes de su expedición, la Ley 715 de 2001 fijó los porcentajes de distribución y destinación específica de los recursos asignados a cada municipio, dejando a los entes territoriales con un bajo margen de maniobra sobre su utilización, salvo un pequeño porcentaje de los recursos correspondientes al denominado propósito general, que en la mayoría de los casos resulta financiando gastos de funcionamiento.

Desde un punto de vistafiscal, los cambios que se dieron con la nueva Constitución fueron básicamente modificaciones al sistema de transferencias (cesión de rentas nacionales). Estas reformas «(...) no introdujeron cambios que permitieran a los gobiernos subnacionales ejercer una 
gestión fiscal diferente. En particular, se mantuvo el mismo sistema de tributación regional y la misma injerencia nacional en la asignación del gasto financiado con los recursos de las transferencias y con los recursos provenientes de algunos impuestos territoriales.» (Iregui, Ramos \& Saavedra, 2001, p. 13).

De otro lado, la legislación le asigna destinación específica a algunos impuestos territoriales, lo que genera una mayor inflexibilidad en el uso de los ingresos tributarios A los problemas anteriores se suma el hecho de que las normas tributarias territoriales fueron escritas sin tener en cuenta la diversidad económica y geográfica de las diferentes regiones del país. Como consecuencia de esto, se presentan casos en los que algunos de los impuestos establecidos no tienen en la práctica aplicabilidad, y sin embargo, no pueden ser sustituidos por un nuevo tributo. Un ejemplo es el impuesto de vehículos, el cual no puede generar un recaudo importante en aquellas localidades donde el principal medio de transporte no es el vehículo, o carece de vías de comunicación que lo permitan.

El hecho de que las reformas de los noventa no consideraran modificaciones al sistema tributario regional es inconsistente con el nuevo esquema de competencias. Por ello, Iregui, Ramos y Saavedra (2001, p. 11) afirman:

Los gobiernos subnacionales debieron asumir nuevas responsabilidades sin tener la posibilidad de generar recursos fiscales diferentes a las transferencias y a los que les brindaba el sistema previo a las reformas. La imposibilidad para generar nuevas rentas es mucho más grave cuando se reconoce que los impuestos que recaudan estos gobiernos son los menos dinámicos y los de más baja elasticidad.

La poca flexibilidad para generar rentas propias lleva a que los gobiernos territoriales dependan de las transferencias del Gobierno nacional. De hecho, este tipo de trasferencias nacionales constituye la fuente de ingresos más importante para la mayoría de los departamentos y municipios del país, circunstancia a la cual el departamento de Boyacá no escapa, pues el $94,3 \%$ de sus municipios se encuentran clasificados, según la Ley 617 de 2000, en categoría sexta, con una amplia dependencia de los recursos transferidos desde el nivel central y escasa posibilidad de generar recursos propios.

\section{LAS TRANSFERENCIAS COMO EJE DE LADESCENTRALIZACIÓN}

Las transferencias territoriales son el mecanismo por medio del cual se ha venido financiando la descentralización en Colombia, pues el Gobierno traslada no solocompetencias y responsabilidades a los entes territoriales, sino que les envía recursos para su financiación. Ese esquema se ha mantenido desde 
mediados de la década del $80 \mathrm{y}$, gracias al nuevo marco constitucional, se ha profundizado.

El inicio de la descentralización fiscal se hizo a través del situado fiscal, creado desde 1968, como un mecanismo de transferencias del Gobierno central a los departamentos, los territorios nacionales y el Distrito Especial de Bogotá, donde el monto de los recursos transferidos correspondía a un porcentaje de los ingresos ordinarios de la nación (sin incluir los no tributarios) y estaban destinados a cubrir los gastos de educación y salud a nivel territorial (Iregui, Ramos, \& Saavedra, 2001).

Más adelante, con la Constitución de 1991 y la Ley 60 de 1993, se fijaron dos clases de transferencias: el situado fiscal, dirigido a los departamentos y distritos, y la participación de los municipios en los ingresos de la nación. A ellos hay que añadir las transferencias complementarias al situado fiscal para educación, que profundizó el proceso de descentralización fiscal, lo que se evidencia en el incremento de la participación de los entes territoriales en los recaudos de la nación, que pasaron del $13 \%$ en 1991 al $50 \%$ en 2011 (Rincón, Ramos, \& Lozano, 2004).

Este aumento en el nivel de participación de las transferencias también se observa en el gasto, ya que, como lo afirman Rincón, Ramos y Lozano (2004), las transferencias representaron el $25 \%$ del incremento total del gasto entre $1990 \mathrm{y}$
2001, equivalente a pasar del $2,4 \%$ al $5,7 \%$ del PIB.

La participación creciente de las transferencias en el gasto del Gobierno central y el uso poco eficiente de estas por parte de los gobiernos territoriales, motivó la expedición del Acto Legislativo 001 de 2001 y la Ley 715 del mismo año, normas que modificaron el monto, criterios de asignación y destinaciones de los recursos transferidos. La reforma constitucional unificó las transferencias en el denominado sistema general de participaciones (SGP) y ligó su comportamiento a los ingresos corrientes de la nación según fuera el crecimiento real promedio de los últimos cuatro años. Además, en el SGP se incluyó a los departamentos, los distritos, los municipios y los resguardos indígenas, a diferencia del situado fiscal que contemplaba departamentos y distritos.

Conforme a la Ley 715 de 2001 (artículo $2^{\circ}$ ), los recursos del SGP se destinan prioritariamente a la financiación de la prestación de los servicios de educación y salud, correspondiendo el 58,5\% a educación y el $24,5 \%$ a salud, mientras que el $17 \%$ se orienta a propósito general (agua potable y saneamiento básico, vivienda de interés social, cultura y deporte, entre otros, pero sin asignaciones específicas) y el restante $4 \%$ se reserva para el Fondo Nacional de Pensiones de las Entidades Territoriales (Fonpet), los resguardos indígenas, los municipios ribereños al río Magdalena y a la alimentación escolar (Clavijo, Vera \& Vera, 2013). 
Esta reforma al régimen de transferencias permitió reducir la participación del SGP dentro de los ingresos corrientes de la nación, pasando del 40.7 al $28.9 \%$ entre los años 2002 y 2008 (Clavijo, Vera, \& Vera, 2013, p. 30). Pero como el Acto Legislativo 001 de 2001 dispuso que en el año 2009 las transferencias volverían a estar atadas al crecimiento promedio de los ingresos corrientes de la nación en los últimos cuatro años, el Gobierno central consideró que ello presionaría el gasto al alza, por lo que tramitó una nueva reforma, promulgada mediante el Acto Legislativo 004 de 2007, el cual amplió el periodo de transición hasta el año 2016, para asegurar que el crecimiento de las transferencias se estabilizara en un $4 \%$ real (Clavijo, Vera, \& Vera, 2013), no obstante que los compromisos de gastos de los entes territoriales, dadas las necesidades sociales por cubrir, pudieran crecer por arriba de ese valor.

En ese sentido, al revisar las iniciativas del Gobierno central dirigidas a reducir los niveles de pobreza, se encuentra que ejemplos como el Plan Nacional de Rehabilitación, el Plan Colombia, la Red de Solidaridad Social, Acción Social y el Departamento para la Prosperidad Social, con sus programas, «(...) todos han sido acciones aleatorias, circunstanciales, y dependientes de la Presidencia de la República; no obedecen a una «política de Estado», sino a la política social del presidente de turno» (Restrepo, 2004, p. 88).
Como ya se mencionó, las materias descentralizadas están todas en la órbita de las políticas sociales, en particular, de acuerdo con lo dispuesto por la Ley 715 de 2001, el grueso de los recursos es absorbido por dos sectores: la educación y la salud, en sus niveles básicos. Sin embargo, tres inquietudes matizan estos desempeños: la eficiencia, la equidad y la sostenibilidad de semejante esfuerzo (Restrepo, 2004, p. 87), sin entrar a evaluar la calidad de prestación de tales servicios, cuyos recursos han sido capturados por el sector privado.

El nivel creciente del gasto del Estado frente a la eficiencia y la evolución de las fuentes de financiamiento llevó a que una de las conclusiones a las que llegó la Comisión de Racionalización del Gasto y de las Finanzas Públicas (Rosas, 1996, p. 25) es que las causas del desequilibrio fiscal del sector público obedecen a la rápida expansión del gasto superando la eficiencia y sostenibilidad de los ingresos, las grandes rigideces del proceso presupuestal, especialmente en las transferencias derivadas de la descentralización, la falta de cobertura institucional y las fallas en la información y la fuerte presión política por un gasto público creciente, el cual generalmente va en beneficio de reducidos grupos particulares (los denominados «rentseekers») y no de los ciudadanos en general.

A pesar de ello, para la visión neoinstitucionalista, la existencia de los 
rent-seekers es justificada, pues como lo afirma Wiesner (1997, p. 123):

(...) los rent-seekers no deben ser descalificados como apátridas, como personas sin sensibilidad social, movidos solamente por su rapacidad. Son, simplemente, agentes económicos haciendo uso de su escogimiento racional para maximizar beneficios. De nada sirve reclamarles que sean generosos y abnegados ciudadanos. Si las condiciones se dan para que ellos puedan capturar rentas lo harán.

En contraste, para algunos analistas como Restrepo (2004), la descentralización trae consigo beneficios más allá de lo eminentemente financiero, por cuanto tres rasgos fundamentales del Estado y del régimen político colombiano, el centralismo, el presidencialismo y el bipartidismo, han sufrido un deterioro importante en los últimos 15 años, producto de la descentralización.

A pesar de que el modelo descentralizador ha reducido la presencia del Estado, un analista económico de actualidad como Piketty (2014) plantea que la crisis actual ha llevado a un «retorno al Estado» donde la presencia y acción del Estado es más activa que nunca y en ese sentido, la fiscalidad no es una cuestión técnica. Es sobre todo un problema político y filosófico, tal vez la más importante de todas las cuestiones políticas. Esto siempre ha sido así. En el corazón de cada agitación política importante radica una revolución fiscal.

\section{ESTIMACIÓN DE LA RELACIÓN D E C A US A L IDA D D E LA DEPENDENCIA FISCAL DE LOS MUNICIPIOS DE SEXTA CATEGORÍA DE BOYACÁ}

El departamento de Boyacá cuenta con 123 municipios, que se han clasificado acorde con lo estipulado en el artículo 2 de la Ley 617 de 2000, correspondiendo 116 de ellos a la sexta categoría ${ }^{2}$, es decir que son municipios con población igual o inferior a diez mil (10.000) habitantes o con ingresos corrientes de libre destinación anuales no superiores a quince mil (15.000) salarios mínimos mensuales legales vigentes $\quad(\$ 9.240$ millones aproximadamente, para el año 2014), o ambas situaciones a la vez, teniendo en cuenta que prima la condición presupuestal a la hora de hacer dicha clasificación. Lo anterior indica que el 94,3\% de los municipios boyacenses se ubica en la más baja categoría territorial, debido a su nivel poblacional y, sobre todo, a su reducida capacidad de generar recursos propios de libre destinación.

En consecuencia, para la realización de la estimación se utilizaron algunos de los indicadores de gestión financiera

$2 \quad$ Para el año 2014, según el DNP, 116 municipios de Boyacá se clasificaron como de sexta categoría de acuerdo con la ley 617 de 2000. Los otros 7 municipios del departamento que se clasificaron en categorías superiores son Tunja $\left(2^{a}\right)$, Sogamoso $\left(3^{a}\right)$, Duitama $\left(3^{a}\right)$, Nobsa $\left(4^{a}\right)$, Puerto Boyacá $\left(4^{a}\right)$, Chiquinquirá $\left(5^{a}\right)$ y Paipa $\left(5^{a}\right)$. 
establecidos por el $\mathrm{DNP}^{3}$, los cuales fueron calculados para cada uno de los 116 municipios de referencia, utilizando como insumo la información de ejecuciones presupuestales que reporta el DNP, cifras que corresponden al periodo 1996-2012 $\mathrm{y}$ que fueron deflactadas, quedando expresadas en pesos constantes del año 2008. Adicionalmente, una vez calculados tales indicadores individualmente para cada municipio, se procedió a calcular el promedio del indicador para los 116 entes territoriales.

El método econométrico utilizado es el de datos de panel, el cual permite realizar un estudio más completo de los datos, ya que posibilita captar en un único análisis el aspecto temporal e individual (también llamado transversal) de los datos manejados. En este sentido, los datos de panel logran aumentar la eficiencia de las estimaciones realizadas, puesto que aumentan el número de datos muestrales que se utilizan en el análisis, cuantificando de una forma más exacta frente a los estudios que utilizan solo análisis temporal o transversal para estimar los impactos de unas variables sobre otra (Wooldridge, 2010).

Por lo anterior, la estimación del modelo econométrico que permite establecer la determinación del comportamiento de la dependencia fiscal en los municipios de sexta categoría de Boyacá, se hizo con el método de datos de panel y utilizando efectos fijos y temporales.
Así, los municipios de sexta categoría constituyen las unidades de corte transversal y los años la variable de serie de tiempo.

De acuerdo con los planteamientos esbozados en el acápite anterior, así como las evidencias empíricas del comportamiento de los indicadores de gestión financiera, las variables que logran explicar significativamente la variabilidad de la dependencia fiscal corresponden, en primer lugar, a factores de tipo fiscal, como la variación marginal del recaudo, la relación entre ingresos tributarios y los ingresos totales, los gastos de funcionamiento en relación a ingresos corrientes de libre destinación y la capacidad de autofinanciamiento de la inversión; por su parte, la variable de población permite controlar por el tamaño de los municipios.

Dada la importante influencia de la política sobre la definición de los presupuestos locales y nacionales, han sido incluidas variables políticas que intentan reflejar esta influencia sobre la dependencia fiscal tales como los años de elecciones presidenciales y de alcaldes. Adicionalmente, se incluye una variable normativa que describe el cambio en la normatividad de las trasferencias ocurrido en el año 2001 (Ley 715701), y el índice de Necesidades Básicas Insatisfechas (NBI) como un indicador del grado de avance social de cada municipio.

$3 \quad$ Para tal fin se siguió el Manual de técnicas para el análisis de la gestión financiera de las entidades territoriales, documento emanado del Departamento Nacional de Planeación -DNP- (2008). 
Debido a la estructura de la información tipo panel, es necesario involucrar efectos temporales para aislar la influencia de variables temporales, como ciclos políticos, cambios normativos y evolución de la economía, los cuales tienen efecto sobre el grado de dependencia fiscal de los municipios de categoría sexta. Adicionalmente, se recogen efectos fijos para cada uno de los municipios mediante variables binarias, dentro de los cuales se pueden establecer aquellos factores diferenciales para cada una de las entidades entre sí que afectan la dependencia pero que son invariantes en el tiempo.

Adicionalmente, el modelo se estimó utilizando errores estándar robustos, para corregir la posible presencia de heterocedasticidad. Con base en lo anterior, la especificación del modelo es la siguiente:

$$
\begin{gathered}
\text { Nivel de dependencia } \text { fiscal }_{i t}=\beta_{0}+\beta_{1} \text { Esfuerzo fiscal }_{i t}+\beta_{2} \text { Ing.Trib./Ing. Totales }_{i t} \\
+\beta_{3} \text { Gastos Func./Ing. Corr.LD }_{i t}+\beta_{4} \text { Autofinac. Inversión }_{i t}+\beta_{5} \text { Población }_{i t} \\
+\beta_{6} \text { Politica Presidencial }_{i t}+\beta_{7} \text { Política Alcaldes }_{i t}+\beta_{8} \text { Cambio SGP }_{i t} \\
+\beta_{9} N B I(2005)_{i t}+E F_{i}+E T_{t}+e_{i t}
\end{gathered}
$$

Donde $i$ corresponde al municipio de sexta categoría y $t$ al año.

En la Tabla 1 se relacionan las variables que se utilizan, su medición y las fuentes de información.
A continuación, en la Tabla 2 se registran los resultados de las estimaciones para el nivel de dependencia fiscal de los municipios de sexta categoría de Boyacá, bajo la metodología de datos de panel y mínimos cuadrados ordinarios (MCO), calculado con errores estándar robustos para evitar la presencia de heterocedasticidad. 
Tabla 1. Variables del modelo de dependencia fiscal

\begin{tabular}{|c|c|c|}
\hline VARIABLE & MEDIDA & $\begin{array}{c}\text { FUENTE DE } \\
\text { INFORMACIÓN }\end{array}$ \\
\hline $\begin{array}{l}\text { Nivel de } \\
\text { dependencia fiscal }\end{array}$ & $\begin{array}{l}\text { Participación porcentual de las } \\
\text { transferencias (SGP) dentro de los } \\
\text { ingresos totales del municipio }\end{array}$ & $\begin{array}{l}\text { Ejecuciones presupuestales } \\
\text { para municipios (DNP) }\end{array}$ \\
\hline Esfuerzo fiscal & $\begin{array}{l}\text { Variación interanual del recaudo } \\
\text { tributario frente a los ingresos totales } \\
\text { del municipio }\end{array}$ & $\begin{array}{l}\text { Ejecuciones presupuestales } \\
\text { para municipios (DNP) }\end{array}$ \\
\hline Ing. trib./ ing. totales & $\begin{array}{l}\text { Participación porcentual de los } \\
\text { ingresos tributarios dentro de los } \\
\text { ingresos totales del municipio }\end{array}$ & $\begin{array}{l}\text { Ejecuciones presupuestales } \\
\text { para municipios (DNP) }\end{array}$ \\
\hline $\begin{array}{l}\text { Gastos func./ing. } \\
\text { corr. LD }\end{array}$ & $\begin{array}{l}\text { Participación de los gastos de } \\
\text { funcionamiento en los ingresos } \\
\text { corrientes de libre destinación del } \\
\text { municipio }\end{array}$ & $\begin{array}{l}\text { Ejecuciones presupuestales } \\
\text { para municipios (DNP) }\end{array}$ \\
\hline Autofinac. inversión & $\begin{array}{l}\text { Relación entre el ahorro corriente y } \\
\text { los gastos de inversión por parte del } \\
\text { municipio }\end{array}$ & $\begin{array}{l}\text { Ejecuciones presupuestales } \\
\text { para municipios (DNP) }\end{array}$ \\
\hline Población & $\begin{array}{l}\text { Número de habitantes del municipio } \\
\text { según los resultados del Censo DANE } \\
2005\end{array}$ & DANE \\
\hline Política presidencial & $\begin{array}{l}\text { Variable binaria igual a } 1 \text { para los años } \\
\text { de elección presidencial }(1994,1998, \\
2002,2006 \text { y 2010) y } 0 \text { para los demás } \\
\text { años }\end{array}$ & $\begin{array}{l}\text { Registraduría Nacional del } \\
\text { Estado Civil }\end{array}$ \\
\hline Política alcaldes & $\begin{array}{l}\text { Variable binaria igual a } 1 \text { para los años } \\
\text { de elección de alcaldes (1994, 1997, } \\
2000,2003,2007 \text { y 2011) y } 0 \text { para los } \\
\text { demás años }\end{array}$ & $\begin{array}{l}\text { Registraduría Nacional del } \\
\text { Estado Civil }\end{array}$ \\
\hline Cambio SGP & $\begin{array}{l}\text { Variable binaria igual a } 1 \text { para los años } \\
\text { posteriores a 2001 (cuando se expide } \\
\text { la Ley } 715701 \text { ) y } 0 \text { para los años } \\
\text { anteriores }\end{array}$ & \\
\hline NBI (2005) & $\begin{array}{l}\text { Nivel de necesidades básicas } \\
\text { insatisfechas del municipio de según } \\
\text { en Censo DANE } 2005\end{array}$ & DANE \\
\hline EF (efecto fijo) & $\begin{array}{l}\text { Variable binaria para cada } \\
\text { municipio }\end{array}$ & \\
\hline ET (efecto temporal) & $\begin{array}{l}\text { Variable binaria para cada año, desde } \\
1996 \text { hasta } 2012\end{array}$ & \\
\hline
\end{tabular}

Fuente: el autor. 
Apuntes Cenes Vol. 34, Nº. 60, ISSN 0120-3053

julio - diciembre 2015, Págs. 215-246

Tabla 2. Modelo de dependencia fiscal para los

municipios de sexta categoría de Boyacá

\begin{tabular}{|c|c|c|c|c|c|c|}
\hline \multicolumn{6}{|c|}{$\begin{array}{l}\text { Number of obs } \\
\text { F(136, 1766) } \\
\text { Prob > F } \\
\text { R-squared } \\
\text { Adj R-squared } \\
\text { Root MSE }\end{array}$} & $\begin{array}{r}1903 \\
19.8200 \\
0.0000 \\
0.6042 \\
0.5737 \\
8.4191\end{array}$ \\
\hline Variable & Coef. & $\begin{array}{l}\text { Std. Err. } \\
\text { Robusto }\end{array}$ & $\mathbf{t}$ & $P>t$ & $\begin{array}{l}{[95 \%} \\
\text { Conf. }\end{array}$ & Interval] \\
\hline Constante & 51.29538 & 4.287 & 11.96 & 0.000 & 42.886 & 59.704 \\
\hline Esfuerzo Fiscal & -0.00406 & 0.002 & -1.710 & 0.087 & -0.009 & 0.001 \\
\hline Ing. Trib./Ing. Totales & -0.30630 & 0.052 & -5.910 & 0.000 & -0.408 & -0.205 \\
\hline Gastos Func./Ing. Corr.LD & 0.02639 & 0.011 & 2.460 & 0.014 & 0.005 & 0.047 \\
\hline Autofinanc. Inversión & -0.00060 & 0.000 & -2.780 & 0.005 & -0.001 & 0.000 \\
\hline Población & -0.00020 & 0.000 & -0.580 & 0.561 & -0.001 & 0.000 \\
\hline Política Presidencial & -0.45313 & 1.184 & -0.380 & 0.702 & -2.775 & 1.869 \\
\hline Política Alcaldes & -7.78158 & 1.120 & -6.950 & 0.000 & -9.978 & -5.585 \\
\hline Cambio SGP & 2.81777 & 1.245 & 2.260 & 0.024 & 0.376 & 5.259 \\
\hline NBI (2005) & 0.17414 & 0.079 & 2.200 & 0.028 & 0.019 & 0.329 \\
\hline
\end{tabular}

Fuente: cálculos del autor con base en la información antes referida

Los resultados de la estimación indican que las variables exógenas seleccionadas tienen un efecto significativo sobre la dependencia fiscal de los municipios de sexta categoría de Boyacá, lo que corrobora varias de las relaciones de comportamiento de tales variables, analizadas anteriormente. Se observa que el nivel de dependencia fiscal está impactado positivamente por la relación entre los gastos de funcionamiento y los ingresos corrientes de libre destinación, el índice de NBI de cada localidad y el cambio en el régimen de transferencias establecido por la Ley 715 de 2001, por la cual se creó el sistema general de participaciones. Este efecto positivo señala que en la medida en que los municipios incrementen la proporción que representan los gastos de funcionamiento frente a los ingresos corrientes de libre destinación, será indicativo de que se están incrementando los gastos de funcionamiento, lo que limita las posibilidades de la administración municipal para disponer de recursos para otras destinaciones, o que se está disminuyendo la generación de ingresos corrientes, o ambas situaciones a la vez, que en últimas muestran fallas en la eficiencia administrativa y aumenta la dependencia fiscal del ente territorial (el coeficiente tiene como valor 0,02638 ).

El coeficiente de impacto del NBI del Censo 2006 sobre la endógena es igual a 0,17414, 
lo que indica que a mayor nivel de NBI de los municipios, mayor será la dependencia fiscal, ya que este índice de pobreza es uno de los criterios utilizados por el gobierno nacional para establecer la asignación de los recursos del SGP transferidos a los entes territoriales, de manera que a mayor nivel de pobreza, mayores serán los recursos transferidos.

La variable de cambio SGP muestra un coeficiente positivo $(2,81777)$, lo cual se explica por el impacto que tuvo el cambio en el régimen de transferencias implementado por la Ley 715 de 2001 sobre la dependencia fiscal, hecho que se evidencia al comparar el promedio del nivel de dependencia fiscal, el cual pasa de 59,6 para el periodo 1996-2001 a 62,6 para los años 2002-2012. Si bien es cierto el SGP aumentó los recursos transferidos y aseguró la destinación de los mismos, de igual manera acrecentó los niveles de dependencia fiscal, especialmente en los entes territoriales más pequeños, como los municipios de sexta categoría objeto de estudio.

El modelo estimó además una relación negativa entre el nivel de dependencia fiscal y variables como el esfuerzo fiscal $(-0,00406)$, la proporción entre ingresos tributarios e ingresos totales municipales $(-0,30630)$, el grado de autofinanciamiento de la inversión $(-0,00060)$, y la población de los municipios $(-0,00020)$. De estas variables hay que destacar la importancia que tiene la capacidad tributaria de los municipios para generar sus propias rentas como factor mitigador de la dependencia fiscal, pues en la medida en que los municipios logren mejorar sus niveles de recaudo, previa actualización de sus catastros urbanos y rurales, así como de sus censos comerciales e industriales (donde existan estas actividades), podrán incrementar sus ingresos producto de gravámenes y ganar algo de autonomía en la utilización de recursos. Sin embargo, teniendo en cuenta que los impuestos de carácter municipal en las localidades pequeñas no aumentarán lo suficiente con estas acciones, se requerirá que el Gobierno central traslade otras rentas a los entes territoriales, no bajo la modalidad de transferencias sino como recaudo directo (rentas propias).

Ligado a este comportamiento está el del esfuerzo fiscal, ya que si la capacidad de recaudo tributario es limitada, la variación del mismo no sufrirá cambios sustanciales entre un año y otro; de ahí el bajo valor del coeficiente, cuyo comportamiento es recogido en parte por el efecto fijo. Similar análisis puede hacerse para el caso del bajo impacto que tiene el autofinanciamiento de la inversión $(-0,0006)$ y la población $(-0,0002)$, cuyos cambios marginales interanuales se recogen por el efecto fijo, ya que si, por un lado, no mejora el recaudo y la variación de este es marginal $y$, por otro, los cambios poblacionales son moderados, no se puede esperar efectos considerables de estas variables sobre el nivel de dependencia fiscal. 
Finalmente, el modelo incorpora dos variables dummy que recogen el posible impacto que los ciclos políticos pueden generar sobre el comportamiento del nivel de dependencia fiscal. En primera instancia se introdujo la variable política presidencial para indicar el impacto que tiene la campaña electoral para elegir mandatario nacional sobre el grado de dependencia fiscal en ese año, ya que como mecanismo de capturar el electorado, el Gobierno nacional aumenta las partidas presupuestales destinadas a las regiones, ya sean inversiones o programas sociales de focalización de gasto, pero ejecutados dichos gastos por el nivel central, lo que hace que en la composición del presupuesto nacional se amplíen estos rubros a costa de disminuir el ritmo de crecimiento de las transferencias, en especial las dirigidas a municipios pequeños con bajo potencial de sufragantes, acción que reduce temporalmente la dependencia fiscal de las localidades, situación que desaparece al año siguiente de electo el nuevo mandatario. Por ello, el coeficiente de impacto de las elecciones presidenciales tiene signo negativo, a pesar de que se reduce de $-2,2$ a $-0,4$ y se vuelve menos significativo cuando se introduce el efecto fijo en el modelo, lo que significa que hay un efecto político nacional que es recogido por el componente fijo, tal como pueden ser las preferencias políticas, el voto cautivo y la cultura política de cada municipio.

Y el impacto político a nivel local se recoge en la variable política alcaldes, para señalar el impacto negativo $(-7,78)$ que tiene el proceso electoral local sobre la dependencia fiscal, ya que en los años de campañas políticas para elegir autoridades territoriales se pueden generar dos fenómenos: uno es el aumento de los recursos orientados por el nivel central al nivel territorial pero no por el canal del SGP sino de partidas específicas para cofinanciación de proyectos, gestionados gracias al entronque entre la clase política de ámbito nacional (parlamentarios) y sus bases políticas en las localidades, donde la una gestiona recursos para favorecer políticamente a las otras, tratando de incidir así en los resultados electorales; es así como esta práctica hace que aumenten los ingresos de capital, y por tanto los ingresos totales, reduciendo así la dependencia fiscal. El otro fenómeno consiste en que al finalizar un periodo de gobierno, época electoral para el siguiente, los mandatarios municipales logran que los concejos municipales aprueben empréstitos dirigidos a ejecutar inversiones, especialmente en infraestructura, lo que incrementa los ingresos de capital, los ingresos totales y disminuye, al menos temporalmente, el nivel de dependencia fiscal.

En conjunto, las variables y los impactos antes descritos contribuyen a explicar el comportamiento y evolución del nivel de dependencia fiscal de los municipios de sexta categoría de Boyacá, que si bien es cierto depende en parte de dichas variables explicativas, también es claro que una buena parte de dicha dependencia fiscal está originada por circunstancias de tipo estructural como el esquema de 
descentralización implementado, el tamaño de los municipios, el valor del censo catastral, el nivel de actividad económica, la baja gestión de las administraciones locales y la cultura política de la ciudadanía, elementos todos que están contenidos en el valor de la constante del modelo $(51,29)$. En últimas, los resultados señalan que los pretendidos procesos de escogimiento público local, que pregonan los orientadores del modelo fiscal que ha orientado a Colombia durante el periodo de estudio, no se hacen evidentes en los municipios de sexta categoría de Boyacá, donde el alto nivel de dependencia indica que tal escogimiento depende más de las decisiones del Gobierno central y de las lógicas políticas que entrelazan los gobiernos locales y centrales.
Finalmente, para tener una panorámica de la evolución histórica del nivel de dependencia de los municipios de Boyacá, a continuación aparecen varios mapas que muestran el nivel de dependencia fiscal en cinco momentos durante el periodo de estudio, de donde se deduce que alrededor de 86 municipios presentan niveles de dependencia fiscal superiores al $55 \%$, encontrando municipios como Chita, Mongua, Panqueba, Paya, Socotá, Tipacoque y Tunugnuá, entre otros, donde el nivel de dependencia fiscal supera el 80 $\%$. Así, en términos generales, se observa que la dependencia fiscal aumenta para los años 2000, 2004 y 2008, en tanto que para el año 2012 la situación mejora un poco, sin que ello sea indicador de avance, sino de una reducción del problema.

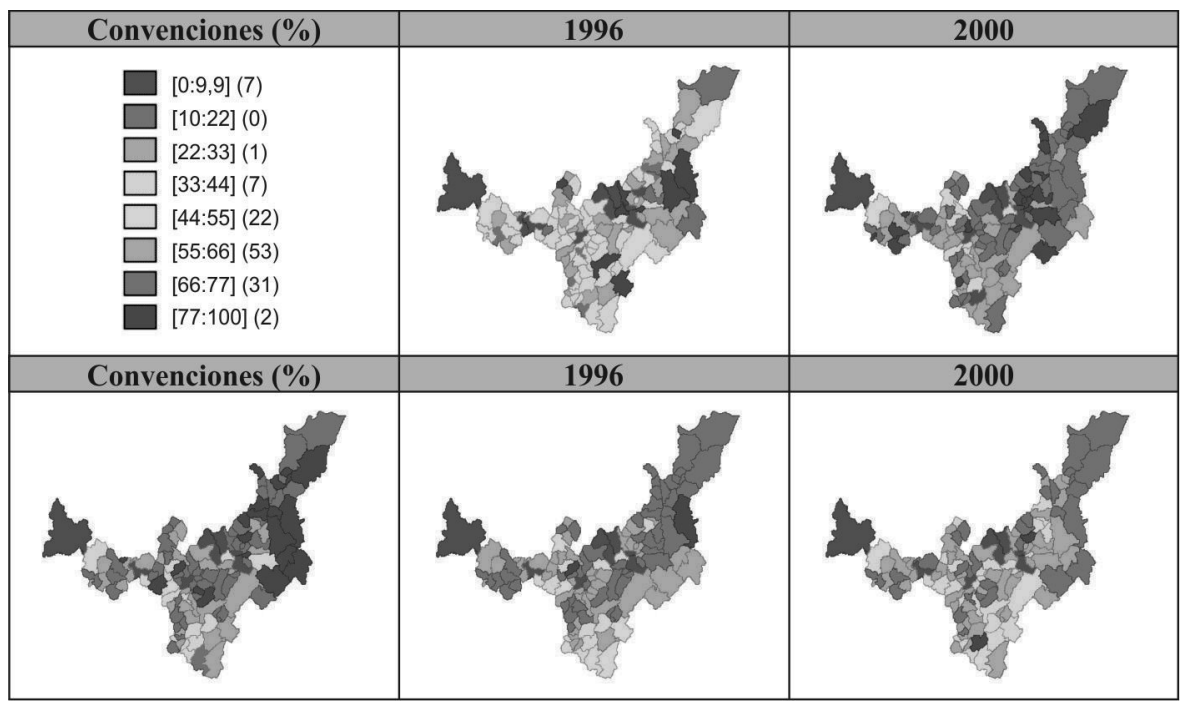

Mapa 1. Nivel de dependencia fiscal de los municipios de sexta categoría de Boyacá.

Fuente: el autor. 


\section{CONCLUSIONES}

El proceso de descentralización política, administrativa y fiscal implementado en Colombia ha venido trasladando permanentemente a los entes territoriales las responsabilidades y competencias que estaban a cargo del Estado central, así como les ha dado participación en las principales rentas, sin que estas se compadezcan del sinnúmero de compromisos que ahora deben asumir las administraciones locales. Por ello, la descentralización hizo que la nación cediera responsabilidades a los entes territoriales, pero sin ceder las rentas tributarias, por lo que se estableció un sistema de transferencias para dar participación a los gobiernos locales en los ingresos que recauda el Gobierno central, es decir que se descentralizaron los gastos mientras el Gobierno central nacional se quedó con los ingresos. Así, la descentralización convirtió a los municipios en dependientes de los giros que son transferidos desde el nivel central, dada la baja capacidad de muchos de ellos para generar rentas propias.

Los municipios objeto de estudio presentan una baja participación de los ingresos tributarios frente a los ingresos totales, la cual obedece al bajo valor que tienen los hechos generadores de estos impuestos, es decir el avalúo catastral (impuesto predial), el monto de las ventas o ingresos brutos de las actividades industriales y comerciales (impuesto de industria y comercio) y el valor de las ventas de combustibles (sobretasa a la gasolina) dentro de la jurisdicción de los municipios objeto de estudio.

Ante esta situación las transferencias se constituyen en la principal fuente de financiación de los municipios, más aún luego de la implementación del SGP en el año 2001. Esto genera una disparidad entre la participación de los ingresos tributarios y las transferencias en los ingresos totales de los municipios que se evidencia en un dato: mientras los primeros tienen, en promedio, una participación del 7,80\%, las otras, en promedio, llegan al $62,9 \%$ durante el periodo de estudio.

La estimación econométrica indica que la dependencia fiscal de los municipios de sexta categoría de Boyacá está determinada por variables que la impactan de forma positiva como la relación entre los gastos de funcionamiento y los ingresos corrientes de libre destinación $(0,026)$, el índice de NBI de cada localidad $(0,1741)$ y el cambio en el régimen de transferencias establecido por la Ley 715 de 2001, por la cual se creó el $\operatorname{SGP}(2,8177)$, mientras que otro conjunto de variables como el esfuerzo fiscal $(-0,00406)$, la proporción entre ingresos tributarios e ingresos totales municipales $(-0,30630)$, el grado de autofinanciamiento de la inversión $(-0,00060)$, y la población de los municipios $(-0,00020)$ tiene un impacto negativo sobre el nivel de dependencia fiscal. Además, hay factores de tipo político como son los procesos de elección presidencial y de autoridades locales, que influyen nega- 
tivamente en la dependencia fiscal, pues si en los años en los cuales se realizan procesos electorales los intereses políticos generan acciones que reducen tal dependencia, son efectos de corto plazo que desaparecen en los demás años, por cuanto el gasto público es manejado por los gobiernos en los meses previos a las elecciones con una racionalidad política antes que económica, en función de intereses electorales específicos.

En suma, puede afirmarse que los factores antes mencionados contribuyen a explicar el comportamiento y evolución del nivel de dependencia fiscal de los municipios de sexta categoría de Boyacá, que si bien es cierto se explica por las variables exógenas seleccionadas, también es claro que una buena parte de dicha dependencia fiscal está originada por circunstancias de tipo estructural como el esquema de descentralización implementado, el tamaño de los municipios, el valor del censo catastral, el nivel de actividad económica, la baja gestión de las administraciones locales y la cultura política de la ciudadanía, elementos todos que están contenidos en el valor de la constante del modelo $(51,29)$. Por ello es que los pretendidos procesos de escogimiento público local, que han orientado a Colombia durante el periodo de estudio, no se hacen evidentes en estos municipios, donde el alto nivel de dependencia indica que tal escogimiento depende más de las decisiones del Gobierno central y de las lógicas políticas que entrelazan los gobiernos locales y centrales. En tal sentido, la pretendida autonomía financiera, que se pregonaba traería la descentralización, no se ha logrado, sino que por el contrario lo municipios, especialmente los más pequeños presupuestalmente hablando, han quedado sometidos a los recursos y destinación que se dé a los mismos desde el Gobierno central, situación que perpetúa sus condiciones de bajo nivel de desarrollo local.

\section{REFERENCIAS}

Buchanan, J. H. (1993). Economía Constitucional. Madrid: Instituto de Estudios Fiscales.

Caballero, C., Galvis, D. \& García M. (2012). Proyecto instituciones ad hoc para municipios en Colombia: intervención ad hoc en municipios colombianos de acuerdo con indicadores sociales. Bogotá: Cifras \& Conceptos S.A.

Clavijo, S., Vera, A. \& Vera, N. (2013). Estructura fiscal de Colombia y ajustes requeridos. Bogotá: Asociación Nacional de Instituciones Financieras.

Departamento Nacional de Planeación -DNP-. (2008). Técnicas para el análisis de la gestión 
financiera de las entidades territoriales. Bogotá: DNP.

Departamento Nacional de Planeación-DNP-. (2011). Desempeño fiscal de los departamentos y municipios: 2011. Bogotá: DNP.

Fondo Monetario Internacional -FMI- (2001). Manual de estadísticas de las finanzas públicas. Washington: FMI.

Fondo Monetario Internacional -FMI- (2001). Manual de programación financiera. Washington: FMI.

Giraldo, C. (2009). Finanzas públicas en América latina. La economía política. (2 ed.). Bogotá: ESAP, Ediciones desde Abajo.

Herrera, A. (2003). Régimen presupuestal de los municipios en Colombia. Revista del Derecho, (19).

Iregui, A., Ramos, J. \& Saavedra, L. (2001). Análisis de la descentralización fiscal en Colombia. Documento de trabajo. Bogotá: Banco de la República.

Ley 617 de 2000. República de Colombia.

Ley 715 de 2001. República de Colombia.

Ley 1473 de 2011. República de Colombia.

Lozano, I. (2009). Caracterización de la política fiscal en Colombia y análisis de la postura frente a la crisis internacional. Borradores de Economía, 1-31.

Piketty, T. (2014). Capital in the twenty-first century. London: The Belknap Press of Harvard University Press.

Rincón, H., Ramos, J. \& Lozano, I. (2004). Crisis fiscal actual: diagnóstico y recomendaciones. Borradores de Economía, 1-112.

Restrepo, D. (2004). De la descentralización a la regionalización. Nuevo escenario de guerra y oportunidad para la paz. Revista Eure, 29(89).

Rincón, H., Ramos, J. \& Lozano, I. (2004). Crisis fiscal actual: diagnóstico y recomendaciones. Borradores de Economía , 1-112.

Rosas, G. (1996). Informe de la Comisión de Racionalización del Gasto y de las Finanzas Públicas. Bogotá: s.n. 
Tiebuot, C.M. (1956, oct.). A pure theory of local expenditures. Journal of Political Economy.

Wiesner, E. (1997). La efectividad de las políticas públicas en Colombia. Un análisis neoinstitucional. (1 ed.). Bogotá: Tercer Mundo.

Wiesner, E. (2006). El orígen político del déficit fiscal en Colombia: contexto institucional 20 años después. Documento CDE 2004-20 . Bogotá: s.n.

Wooldirdge, J. (2010). Econometric analysis of cross section and panel data. Cambridge, Massachusetts: The MIT Press. 